\title{
STUDY OF THE EFFECT OF DIBENZAZEPINE IN RENAL INJURY INDUCED BY CISPLATIN IN RATS
}

\author{
BY \\ Rana H. Abd El-Rhman, Reem N. El-Naga*, Mariane G. Tadros*, Amany M. Gad, \\ Sherifa Hassaneen \\ FROM \\ Department of Pharmacology, The National Organization for Drug Control and \\ Research, Cairo, Egypt \\ * Department of Pharmacology and Toxicology, Faculty of Pharmacy, Ain Shams \\ University, Cairo, Egypt
}

\begin{abstract}
Indeed, cisplatin is a standard anti-cancer agent that is used in the management of different types of solid tumors. Unfortunately, cisplatin significantly accumulates in renal proximal tubular cells where nephrotoxicity is the main side effect limiting its clinical use. The present study was conducted to explore the possible nephroprotective effect of dibenzazepine against cisplatin-induced renal injury in rats. Rats received pretreatment with three different doses of dibenzazepine for one week before giving cisplatin at a one single dose $(7 \mathrm{mg} / \mathrm{kg})$ intraperitoneally. The renal injury was determined by measuring nephrotoxicity markers as well as histopathological investigation. Dibenzazepine attenuated the elevation in blood urea nitrogen and serum creatinine levels. Moreover, the nephroprotective effect of dibenzazepine was further confirmed histopathologically. In conclusion, these findings show that dibenzazepine provides protection against renal injury induced by cisplatin.
\end{abstract}

\section{Introduction}

Cisplatin is an effective chemotherapeutic agent (Miller et al., 2010) where it is used to cure many solid tumors like genitourinary, cervical, head and neck, small cell and non- small cell lung tumors (Rosenberg, 1999).

Treatment with cisplatin is associated with severe side effects (Florea and Büsselberg, 2011). Cisplatin-induced renal toxicity is dose-dependent, limiting the possibility of increasing dosage, which affects treatment effectiveness (Safirstein et al., 1984; Peres and da Cunha, 2013). Cisplatin nephrotoxicity is evident by the decline in the glomerular filtration rate, followed by increased serum level of creatinine and blood urea nitrogen (BUN), hypomagnesemia and hypokalemia (Gomez Campdera et al., 1986; Arany and Safirstein, 2003). Although protective measures are applied, repeated cisplatin dosing leads to irreversible renal damage (Santoso et al., 2003; Taguchi et al., 2005).

Dibenzazepine is known as a gamma-secretase inhibitor (Kopan and IIagan, 2004). Previous studies showed that gamma-secretase inhibitors have both antiproliferative anti-inflammatory activities (Kang et al., 2009; Piggott et al., 2011; Hans 
et al., 2012; Pan et al., 2012). Moreover, dibenzazepine was found to have antiinflammatory (Xiao et al., 2014) as well as anti-cancer activity in a variety of cancer cells (Nickoloff et al., 2003; Curry et al., 2005; Van et al., 2005; Katoh, 2007; Shih and Wang, 2007; Al-Qawasmeh et al., 2009).

\section{Material and methods}

\section{Material}

Cisplatin and dibenzazepine were purchased from Merk Ltd. (Cairo, Egypt) and Sigma Chemical Co. (St. Louis, MO, USA), respectively. The dose of $7 \mathrm{mg} / \mathrm{kg}$ cisplatin was selected according to previous studies (Arjumand and Sultana, 2011; El-Naga, 2014; El-Naga and Mahran, 2016). Used chemicals were obtained from El-Nasr Company (Egypt) of the highest grade commercially available.

\section{Animals}

Male albino rats (150-200 g) were maintained at the animal house of the National Organization for Drug Control and Research (NODCAR, Giza, Egypt). Animals had free access to food and water. They were maintained at $21-24^{\circ} \mathrm{C}$ and 40 $60 \%$ relative humidity with 12 -h light-dark cycle. Animals were subjected to 1 week adaptation period in the animal house before the beginning of the experiments. Experimental procedures were conducted in accordance with the international ethical guidelines for investigations in laboratory animals and were approved by the Research Ethical Committee of Faculty of Pharmacy, Ain shams University (Cairo, Egypt).

\section{Method}

\section{Experimental design}

Animals were randomly divided into five groups (ten animals per group). The first group received the vehicle only and served as the control group. The second group received a single dose of cisplatin $(7 \mathrm{mg} / \mathrm{kg}$ i.p.) to induce acute renal injure. The third, fourth and fifth groups were given different doses of dibenzazepine $(0.25,0.5$ and 1 $\mathrm{mg} / \mathrm{kg} /$ day i.p.), respectively for 12 days starting 7 days before cisplatin administration. At the end of the experiment, blood samples were collected from the retro-orbital plexus and allowed to clot. Serum was used for the assessment of nephrotoxicity markers. Rats were sacrificed and kidney tissues were dissected out, and washed with ice-cold saline. Kidney specimens of each group were fixed in $10 \%$ formalin for histopathological examination.

\section{Assessment of nephrotoxicity markers}

Serum Blood urea nitrogen and serum creatinine levels were assessed using Biodiagnostics kits (Biodiagnostics, Cairo, Egypt). All procedures were performed according to the manufacturer's instructions.

\section{Histopathological examination}

Sections from of the kidney of the different groups were sliced and fixed in $10 \%$ formalin then, embedded in paraffin blocks. Slices of $4 \mu \mathrm{m}$ thickness were stained with Hematoxylin and Eosin $(\mathrm{H} \& \mathrm{E})$ for routine histopathological examination under light microscope. 


\section{Statistical analysis}

Data are presented as mean \pm SD. Multiple comparisons were performed using one-way ANOVA followed by Tukey-Kramer test for post hoc analysis. The 0.05 level of probability was used as the criterion for significance. All statistical analyses were performed using the SPSS version 16 (Chicago, IL, USA), while the graphs were drawn using a prism computer program (GraphPad software Inc. V5, San Diego, CA, USA).

\section{Results}

\section{Nephrotoxicity markers.}

Assessment of nephrotoxicity markers showed that cisplatin induced a significant increase in BUN and serum creatinine by 550.8 and $737 \%$, respectively as compared to the control group. Notably, pre-treatment of intoxicated rats with dibenzazepine of all the tested doses showed a significant decrease in BUN by 11.7, 12.1 and $17.2 \%$, (Fig. 1) and in serum creatinine by 21.9, 33.0 and 52.9\% (Fig. 2) for the dibenzazepine doses of $0.25,0.5$ and $1 \mathrm{mg} / \mathrm{kg}$, respectively as compared to the cisplatin group. The higher dose of dibenzazepine $(1 \mathrm{mg} / \mathrm{kg} /$ day $)$ showed the best nephroprotection when compared to other doses of dibenzazepine.

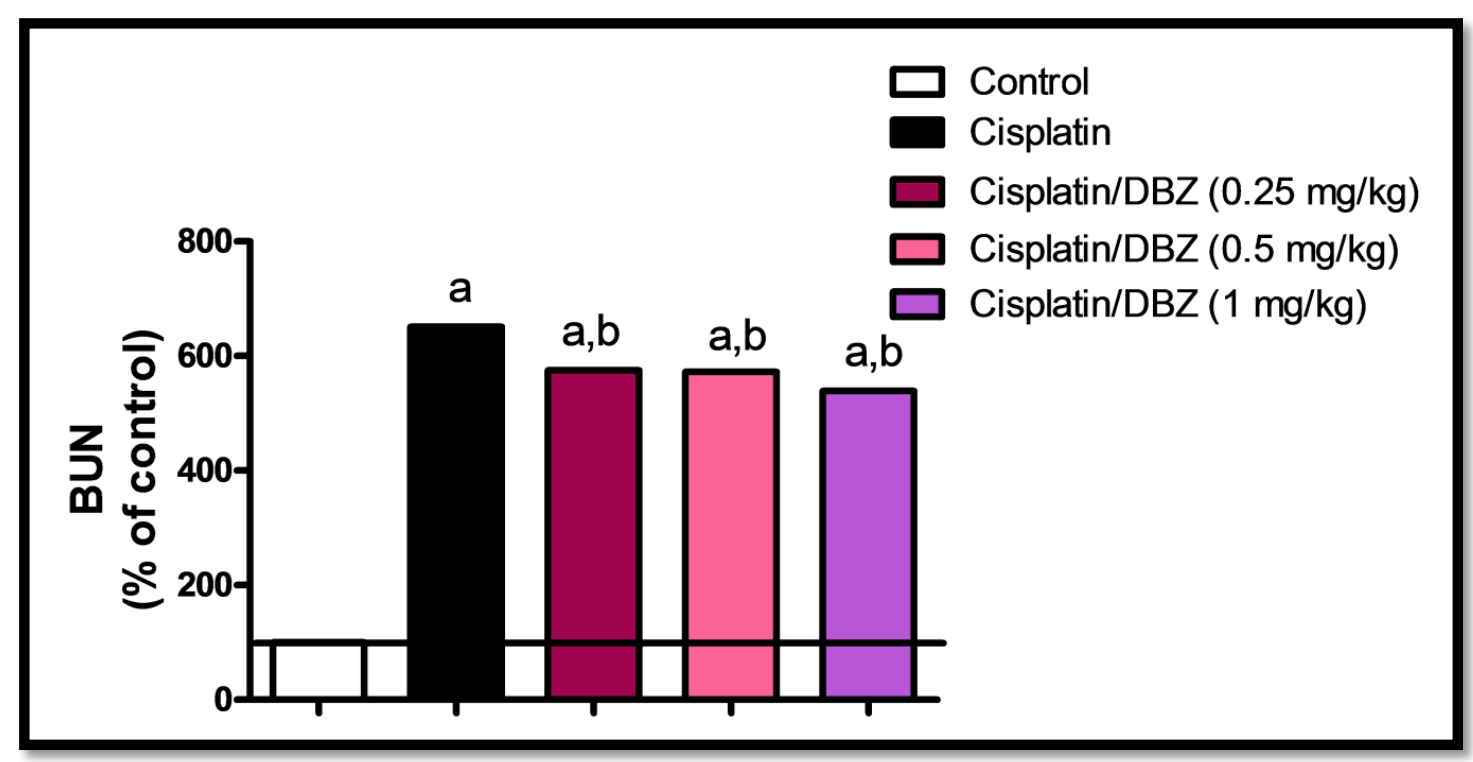

Figure (1): Effect of pre-treatment with different doses of dibenzazepine on blood urea nitrogen levels in cisplatin-induced nephrotoxicity in rats as percentage of control.

a or b: Statistically significant from the control or the cisplatin group, respectively at $\mathrm{P}<0.05$ using ANOVA followed by Tukey-Kramer as a post-hoc test. BUN: blood urea nitrogen; DBZ: dibenzazepine. 


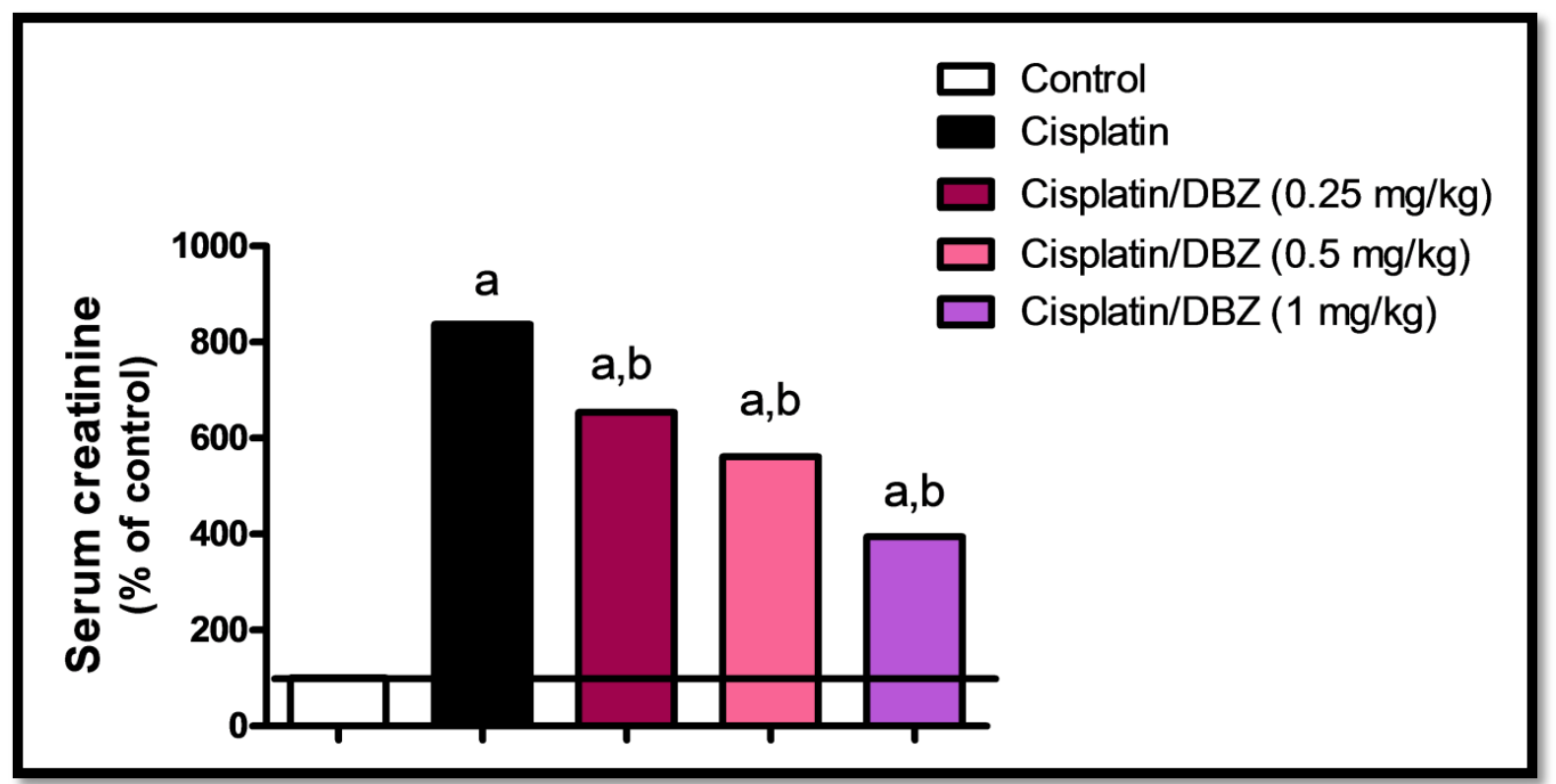

Figure (2): Effect of pre-treatment with different doses of dibenzazepine on serum creatinine in cisplatin-induced nephrotoxicity in rats as percentage of control.

a or b: Statistically significant from the control or the cisplatin group, respectively at $\mathrm{P}<0.05$ using ANOVA followed by Tukey-Kramer as a post-hoc test. DBZ: dibenzazepine.

\section{Kidney pathology.}

Figure 3 shows the effects of the different treatment groups on the histological structure of the kidney. No histopathological alterations and normal histological structure of the glomeruli and tubules at the cortex were recorded in the control group (Figure 3A). Nevertheless, degenerative changes and coagulative necrosis were noticed in the lining epithelium of the tubules at the cortex and medulla with formation of eosinophilic casts in the tubular lumen in kidney specimens taken form cisplatininjected rats (Figure 3B). While the tubular lining epithelium showed degeneration and coagulative necrosis in both cortex and medulla in the group pre-treated with 0.25 $\mathrm{mg} / \mathrm{kg}$ dibenzazepine (Figure 3C). Besides, pretreatment with $0.5 \mathrm{mg} / \mathrm{kg}$ dibenzazepine showed congestion in the blood vessels at the cortex together with degenerative changes and coagulative necrosis in the tubular lining epithelium of cortex and medulla (Figure 3D). Notably, sections of kidney taken from $1 \mathrm{mg} / \mathrm{kg}$ dibenzazepine pre-treated rats, showed only mild necrosis in the lining tubular epithelium at the cortico-medullary junction (Figure 3E). 

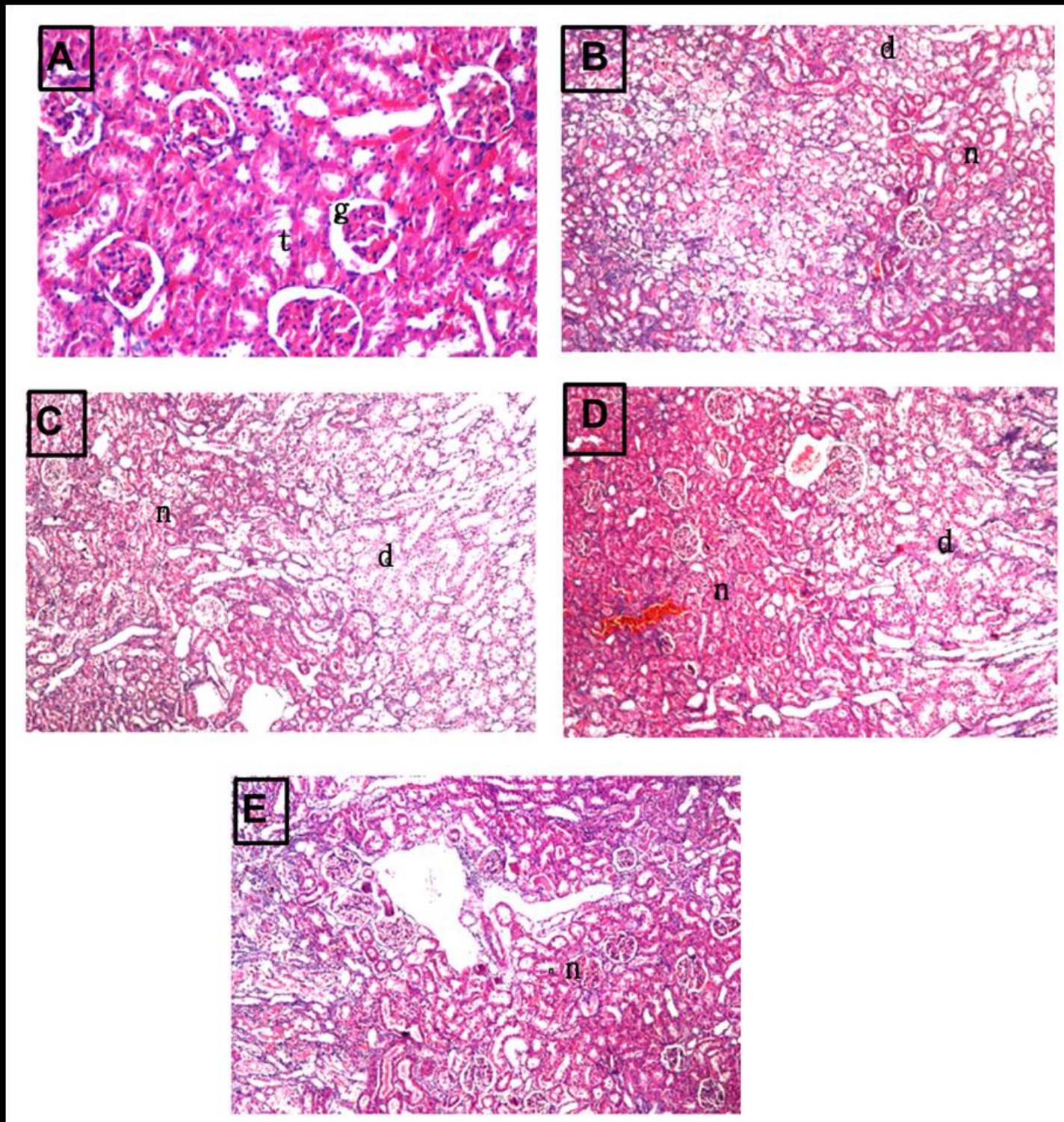

Figure (3): Representative photomicrographs of kidney sections taken from the different treatment groups stained by hematoxylin-eosin stain: A:

Section taken from kidneys of the control rats shows normal structures of glomeruli $(\mathrm{g})$ and tubules $(\mathrm{t})(\times 40)$. B: Section taken from kidney of cisplatin-injected rats shows coagulative necrosis (n) and diffused degeneration (d) in the tubules. Also, eosinophilic casts (c) were observed in tubular lumen $(\times 16)$. C: Section taken from kidney specimens of rats pre-treated with lower dose of dibenzazepine $(0.25 \mathrm{mg} / \mathrm{kg})$ shows degeneration (d) and coagulative necrosis (n) of the tubular lining epithelium in cortex and medulla $(\times 16)$. D: Section taken from kidney specimens of rats pre-treated with middle dose of dibenzazepine $(0.5 \mathrm{mg} / \mathrm{kg})$ shows congestion in blood vessels (c) with degenerative (d) in tubular lining epithelium at the cortex while coagulative necrosis (n) in the epithelial cells lining the tubular at cortico-medullary junction $(\times 16)$. E: Section taken from kidney specimens of rats pre-treated with higher dose of 
dibenzazepine $(1 \mathrm{mg} / \mathrm{kg})$ shows only mild coagulative necrosis (n) in tubular lining epithelium at the cortico-medullary junction $(\times 16)$.

\section{Discussion}

The present study was designed to investigate the potential protective effect of dibenzazepine against cisplatin-induced acute renal injury in rats. This study showed that the renal injury, induced by cisplatin, was manifested by the prominent increase in BUN and serum creatinine levels as compared to the control animals, suggesting the occurrence of acute renal failure. The histopathological findings demonstrated that the administration of cisplatin induced a severe degenerative change. Also, coagulative necrosis was noticed in the lining epithelium of the tubules at the cortex and medulla together with the formation of eosinophilic casts in the tubular lumen. This was in line with previous studies (El-Naga, 2014; El-Naga and Mahran, 2016).

Small molecule inhibitors for gamma-secretase activity have been actively investigated, over the past decades, for their anti-inflammatory effects and neuroprotective effects especially in Alzheimer's disease (Bateman et al., 2009). Besides, some gamma-secretase inhibitors have been tested for the treatment of tumor and cardiovascular diseases (Aoyama et al., 2009; Kang et al., 2009; Acharya et al., 2011). In our study, pre-treatment of cisplatin-injected rats with dibenzazepine markedly attenuated cisplatin-induced changes in nephrotoxicity markers and the histological architecture of the kidney in a dose-dependent manner. A dose of $1 \mathrm{mg} / \mathrm{kg}$ dibenzazepine provided the best nephroprotection. This was evident by the significant decrease in BUN and serum creatinine as compared with cisplatin group. In accordance with this, Xiao and his co-workers (2014) had found that dibenzazepine attenuated kidney fibrosis induced by unilateral ureter obstruction in mice. Indeed, the treatment with anti-inflammatory agents is a promising strategy in reducing cisplatin-induced renal dysfunction and decreasing the histological evidence of injury.

\section{Conclusion}

In conclusion, the present study provides an evidence for the nephroprotective effects of dibenzazepine where the dose of $1 \mathrm{mg} / \mathrm{kg} / \mathrm{day}$ provided the best protection. Further studies may be done to elucidate the underlying molecular mechanisms of the nephroprotective effect of dibenzazepine.

\section{REFERENCES}

Acharya, A., Hans, C.P., Koenig, S.N., Nichols, H.A., Galindo, C.L., Garner, H.R., Merrill, W.H., Hinton, R.B., Garg, V., 2011. Inhibitory role of Notch1 in calcific aortic valve disease. PLoS One. 6(11), e27743.

Al-Qawasmeh, R.A., Lee, Y., Cao, M.Y., Gu, X., Viau, S., Lightfoot, J., Wright, J.A., Young, A.H., 2009. 11-Phenyl-[b,e]-dibenzazepine compounds: novel antitumor agents. Bioorg. Med. Chem. Lett. 19(1), 104-107.

Aoyama, T., Takeshita, K., Kikuchi, R., Yamamoto, K., Cheng, X.W., Liao, L.K., Murohara, T., 2009. Gamma-Secretase inhibitor reduces diet-induced atherosclerosis in apolipoprotein E deficient mice. Biochem. Biophys. Res. Commun. 383 (2), 216-221. 
Arany, I., Safirstein, R.L., 2003. Cisplatin nephrotoxicity. Semin. Nephrol. 23 (5), 460-464.

Arjumand, W., Sultana, S., 2011. Glycyrrhizic acid: a phytochemical with a protective role against cisplatin-induced genotoxicity and nephrotoxicity. Life Sci. 89 (13-14), 422-429.

Bateman, R.J., Siemers, E.R., Mawuenyega, K.G., Wen, G., Browning, K.R., Sigurdson, W.C., Yarasheski, K.E., Friedrich, S.W., Demattos, R.B., May, P.C., Paul, S.M., Holtzman, D.M., 2009. A gamma-secretase inhibitor decreases amyloid-beta production in the central nervous system. Ann. Neurol. 66 (1), 48-54.

Curry, C.L., Reed, L.L., Golde, T.E., Miele, L., Nickoloff, B.J., Foreman, K.E., 2005. Gamma secretase inhibitor blocks Notch activation and induces apoptosis in Kaposi's sarcoma tumor cells. Oncogene. 24 (42), 6333-6344.

El-Naga, R.N., 2014. Pre-treatment with cardamonin protects against cisplatin-induced nephrotoxicity in rats: Impact on NOX-1, inflammation and apoptosis. Toxicol. Appl .Pharmacol. 274 (1), 87-95.

El-Naga, R.N., Mahran, Y.F., 2016. Indole-3-carbinol protects against cisplatininduced acute nephrotoxicity: role of calcitonin gene-related peptide and insulin-like growth factor-1. Sci. Rep. 6:29857.

Florea, A.M., Büsselberg, D., 2011. Cisplatin as an anti-tumor drug: cellular mechanisms of activity, drug resistance and induced side effects. Cancers. 3 (1), 1351-1371.

Gomez Campdera, F.J., Gonzalez, P., Carrillo, A., Estelles, M.C., Rengel, M., 1986. Cisplatin nephrotoxicity: symptomatic hypomagnesemia and renal failure. Int. J. Pediatr. Nephrol. 7 (3), 151-152.

Hans, C.P., Koenig, S.N., Huang, N., Cheng, J., Beceiro, S., Guggilam, A., Kuivaniemi ,H., Partida-Sánchez, S., Garg, V., 2012. Inhibition of Notch1 signaling reduces abdominal aortic aneurysm in mice by attenuating macrophage-mediated inflammation. Arterioscler. Thromb. Vasc. Biol. 32 (12), 3012-3023.

Kang, J.H., Kim, B.S., Uhm, T.G., Lee, S.H., Lee, G.R., Park, C.S., Chung, I.Y., 2009. Gamma-secretase inhibitor reduces allergic pulmonary inflammation by modulating Th1 and Th2 responses. Am. J. Respir. Cri.t Care Med. 179 (10), 875-882.

Katoh, M., 2007. Notch signaling in gastrointestinal tract (review). Int. J. Oncol. 30 (1), 247-251.

Kopan, R., Ilagan, M.X., 2004. Gamma-secretase: proteasome of the membrane?. Nat. Rev. Mol. Cell Biol. 5 (6), 499-504.

Miller, R.P., Tadagavadi, R.K., Ramesh, G., Reeves, W.B., 2010. Mechanisms of cisplatin nephrotoxicity. Toxins (Basel). 2 (11), 2490-2518. 
Nickoloff, B.J., Osborne, B.A., Miele, L., 2003. Notch signaling as a therapeutic target in cancer: a new approach to the development of cell fate modifying agents. Oncogene. 22 (42), 6598-6608.

Pan, L., Li, Y., Jia, L., Qin, Y., Qi, G., Cheng, J., Qi, Y., Li, H., Du, J., 2012. Cathepsin $\mathrm{S}$ deficiency results in abnormal accumulation of autophagosomes in macrophages and enhances Ang II-induced cardiac inflammation. PLoS One. 7 (4), e35315.

Peres, L.A., da Cunha, A.D.Jr., 2013. Acute nephrotoxicity of cisplatin:molecular mechanism. J Bras Nefrol. 35, 332-340.

Piggott, K., Deng, J., Warrington, K., Younge, B., Kubo, J.T., Desai, M., Goronzy, J.J., Weyand, C.M., 2011. Blocking the NOTCH pathway inhibits vascular inflammation in large-vessel vasculitis. Circulation. 123 (3), 309-318.

Rosenberg, B., 1999. Platinum complexes for the treatment of cancer: why the search goes on. In: Lippert, B. (Ed.), Cisplatin, Chemistry and Biochemistry of a Leading Anticancer Drug. Wiley-VCH, Basel, Switzerland, 3-27.

Safirstein, R., Miller, P., Guttenplan, J.B., 1984. Uptake and metabolism of cisplatin by rat kidney. Kidney Int. 25 (5), 753-758.

Santoso, J.T., Lucci III, J.A., Coleman, R.L., Schafer, I., Hannigan, E.V., 2003. Saline, mannitol, and furosemide hydration in acute cisplatin nephrotoxicity: a randomized trial. Cancer Chemother. Pharmacol. 52 (1), 13-18.

Shih, Le.M., Wang, T.L., 2007. Notch signaling, gamma-secretase inhibitors, and cancer therapy. Cancer Res. 67 (5), 1879-1882.

Taguchi, T., Nazneen, A., Abid, M.R., Razzaque, M.S., 2005. Cisplatin-associated nephrotoxicity and pathological events. Contrib. Nephrol. 148, 107-121.

Van, E.S.J.H., van Gijn, M.E., Riccio, O., Born van den, M., Vooijs, M., Begthel, H., Cozijnsen, M., Robine, S., Winton, D.J., Radtke, F., Clevers, H., 2005. Notch/gamma-secretase inhibition turns proliferative cells in intestinal crypts and adenomas into goblet cells. Nature. 435 (7044), 959-963.

Xiao, Z., Zhang, J., Peng, X., Dong, Y., Jia, L., Li, H., Du, J., 2014. The Notch $\gamma$ secretase inhibitor ameliorates kidney fibrosis via inhibition of TGF$\beta / \mathrm{Smad} 2 / 3$ signaling pathway activation. Int. J. Biochem. Cell Biol. 55, 6571. 


\section{دراسة تأثثر ديبينزازيبين في الأضرار الكلوية التي يسببها سيسبلاتين في الجرذان للسادة الاكاترة}

رنا حسن عبد الرحمن- ريم نبيل أبو النجا* ـ مريان جورج تادروس* ـ أماني محمد جادـ شريفة حسانين

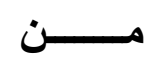

$$
\text { * قسم الفارماكولوجي، الهيئة القومية للرقابة و البحوث الدوائية }
$$

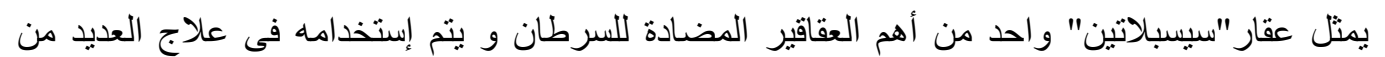

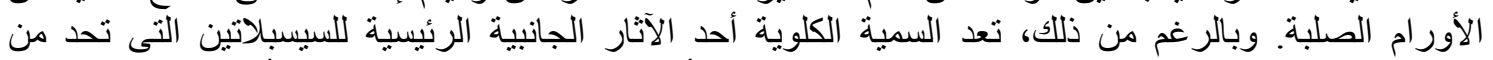

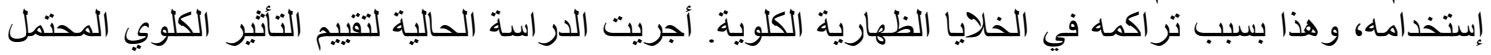

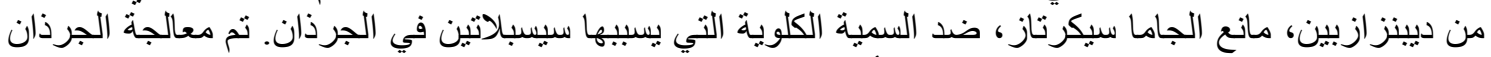

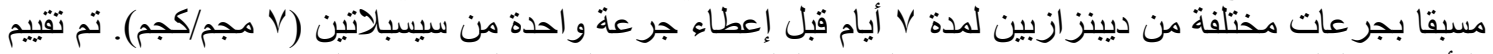

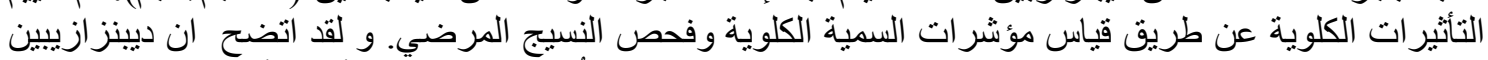

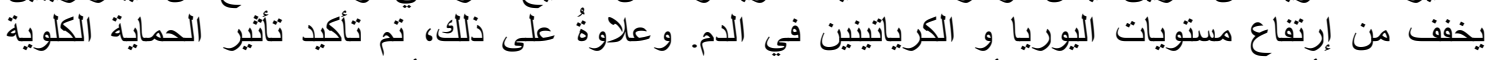

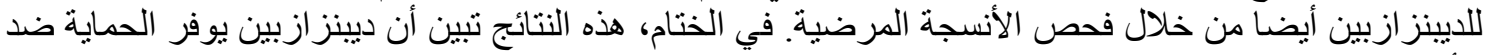

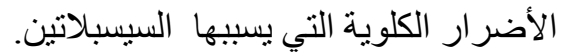

